\title{
CONVERGENCE OF HEALTH CARE EXPENDITURES ACROSS THE US STATES: A RECONSIDERATION
}

\author{
NICHOLAS APERGIS (Corresponding author) \\ Northumbria University, Newcastle upon Tune, U.K. \\ nicholas.apergis@northumbria.ac.uk \\ TSANGYAO CHANG \\ Feng Chia University, Taichung, Taiwan \\ tychang@mail.fcu.edu.tw \\ CHRISTINA CHRISTOU \\ University of Piraeus, Piraeus, Greece \\ christou@unipi.gr \\ RANGAN GUPTA \\ University of Pretoria, Pretoria, South Africa \\ Rangan.Gupta@up.ac.za
}

\section{SUMMARY}

Current evidence on the convergence of health care expenditures across the US states into a single convergence club is non-existent. Against this backdrop, we revise this issue using a modified panel unit root test that accounts for smooth structural changes spanning the period of 1966-2009. The results illustrate that the ratio of the individual health care expenditures relative to the cross-sectional average is broken trend-stationary, not only in the aggregate panel, but also across all 50 US states, as indicated by a sequential panel selection method. In addition, the findings also document that the evidence of convergence in health care expenditures is possibly due to the convergence of personal disposable income across the US states. These results are expected to have important policy implications for the US health care market.

KEY WORDS: Health care expenditures, convergence, unit root test, Fourier function, sequential panel selection methodology 


\section{INTRODUCTION}

Health care expenditures have been on the rise in most developed economies, with it being most pronounced in the US (Wang, 2009). In light of this evidence, studies on OECD economies, including the US, have provided evidence to understanding the data generating process, the sources of this growth in health care expenditures, its impact on economic growth, whether health care expenditures are necessary or luxury goods, and the resulting policy implications (Carrion-i-Silvestre, 2005; Narayan, 2006, 2009, 2010; Narayan and Narayan, 2008a, 2008b; Rettenmaier and Wang, 2006; Narayan et al., 2011; Freeman, 2012; Narayan and Popp, 2012; and references cited therein for detailed literature reviews).

In this paper, our concern is the convergence of real per capita health care expenditures across the US states. While there are quite a few studies that have analyzed the convergence of health care expenditures across OECD countries and the European Union member countries (Hitiris, 1997; Nixon, 1999; Hitiris and Nixon, 2001; Hofmarcher et al., 2004; Okunade et al., 2004; Narayan, 2007; Aslan, 2008; Fallahi, 2011; Pekkurnaz, 2015; and references cited therein). There are other factors ${ }^{1}$, however, that can result in convergence of health care expenditures; the primary reason behind convergence or lack of it is believed to be income. As income

\footnotetext{
${ }^{1}$ For instance, integration in health care markets and common policies related to the promotion of health, living and working conditions, as well as, coordination of health-related research (Wang, 2009).
} 
converges, so does the income-dependent health care expenditures.

Generally speaking, it is believed that convergence of health care expenditures, possibly due to income convergence, is more likely to occur across regions within a country than across countries, given that these regions are relatively more homogenous than countries in terms of economic conditions, policies related to health, technology, the structure of the health industry, consumer preferences, and general features characterizing the health care system (Wang, 2009). Wang (2009) analyzes the convergence of health care expenditures across the US states - which to the best of our knowledge, is the only paper exploring the convergence issue for the US health care system. Using both a standard cross-sectional approach and the time series-based cluster analysis, Wang (2009) documents the movements of real per capita health care expenditures across the 50 US states over the period 1980-2004. He provides favorable evidence that while convergence has occurred across the US states, both in terms of total expenditures and in terms of their major components, the rate of convergence is slow. More importantly, this paper indicates that there is no single nation-wide convergence process, with states converging to number of separate convergent clubs. Specifically, 38 states are found to form 16 convergence clubs of size 2 or 3, with the remaining 12 states being individually separated. Wang (2009), however, warns that even though the critical values of the cluster analysis are based 
on Monte Carlo simulations to account for the short length of the time series, his empirical results should be viewed with caution. From a policy perspective, his results highlight that health policies cannot be uniform across the entire country, but in fact, they need to be similar only within the convergent clubs, implying that health care policies should in fact be implement on the state level, rather than on national level.

Against this backdrop, we revisit the issue of convergence in terms of aggregate real per capita health care expenditures across the US states using an annual dataset spanning the period of 1966-2009. We cast the problem of convergence as a test of stationarity of the ratio of real per capita health expenditures of a specific state relative to the corresponding cross-sectional average across all 50 US states. Given that our sample size is relatively short for time series analysis, we implement a modified version of the Im et al. (IPS, 2003) panel unit root test, as it is widely believed that panel-based approaches can increase the power of time series-based unit root tests, especially in cases where the length of the time series involved is not too long (Chang et al., 2015). Our modifications of the standard IPS test are in two directions. First, given the evidence of structural breaks in the health care expenditures in the US states, as reported by Rettenmaier and Wang (2006) and Freeman (2012), we model structural breaks of an unknown form as a smooth process via means of flexible Fourier transforms (Enders and Lee, 2012). Such an approach is 
preferable over standard methodologies of modeling structural breaks through dummy variables (Carrion-i-Silvestre, 2005; and references cited therein), which implies abrupt changes in the mean and/or trend of a series, which is less likely to be observed in low frequency data (Chang et al., 2015). Moreover, in terms of the dummy variables approach, one has to acknowledge the exact number and location of the breaks. These are not usually known and, therefore, need to be estimated, which in turn, introduces an undesirable pre-selection bias (Maddala and Kim, 1998). By contrast, the flexible Fourier function based approach does not require specifying the maximum number of breaks or imposing a 15-20 percent truncation at the beginning or the end of the data sample, which could also possibly include breaks. By ignoring structural breaks while testing for unit roots, is highly likely to lead to interpreting any departures from structural instabilities as permanent stochastic disturbances, i.e., sway the analysis towards the unit root hypothesis (Canarella et al., 2012).

A result of convergence, i.e., stationarity of our metric, for the entire panel does not indicate which of the states, if not all, are driving these results, since panel-based unit root tests are joint tests of a unit root across all members in a panel. Therefore, we augment the IPS test with a Fourier function by applying the Sequential Panel Selection Method (SPSM), proposed by Chortareas and Kapetanios (2009). The SPSM approach classifies the whole panel into groups of stationary and 
non-stationary series, and hence, it clearly identifies which of the series, if not all, in the panel are stationary processes, driving the stationarity of the entire panel.

Note that, we also apply the modified IPS test to an appropriate metric of the real per capita disposable income across the US states, to check out for the role of income in the convergence process of the health care expenditures. To the best of our knowledge, this is the first paper to have developed and applied this modified IPS test, which accounts for both structural breaks and individual cross-section level stationarity, to analyze convergence in both health care expenditures and disposable income across all 50 US states. The remainder of the paper is organized as follows: Section 2 lays out the basics of the methodology, while Section 3 describes the dataset and reports the results. Finally, Section 4 concludes the paper.

\section{METHODOLOGY}

In this section, we briefly outline the modified IPS test which not only accounts for structural breaks (via the use of Fourier transformation), but it also incorporates the SPSM to clearly identify which of the series, if not all, in the panel could be $\mathrm{I}(0)$ and hence, driving the stationarity of the overall panel.

To analyze whether the real per capita health care expenditures are converging, we need an appropriate metric. To our end, we define: $H E_{i, t}=H C E_{i, t} / \overline{H C E_{t}}$, i.e., the ratio of real per capita health care expenditures for a specific state at a specific point 
in time $\left(H C E_{i, t}\right)$, divided by the cross-sectional average of real per capita health care expenditures across the 50 US states at that same point in time $\left(\overline{H C E_{t}}\right)$. If the real per capita health care expenditures for a specific state $i$ converges, then $H E_{i, t}$ should be a stationary series. Provided that our metric of interest has a time trend for each of the cross-sections (i), as will be discussed below, the system of the modified IPS equations with a Fourier function yields:

$\Delta H E_{i, t}=\xi_{i}+\delta_{i} H E_{i, t-1}+\gamma_{i} t+\sum_{j=1}^{k_{i}} \theta_{i, j} \Delta H E_{i, t-j}+a_{i} \sin \left(\frac{2 \pi k t}{T}\right)+b_{i} \cos \left(\frac{2 \pi k t}{T}\right)+\varepsilon_{i, t}$

where $t=1,2, \ldots ., T$. Note that the standard IPS test excludes the $a_{i} \sin \left(\frac{2 \pi k t}{T}\right)+b_{i} \cos \left(\frac{2 \pi k t}{T}\right)$ part in equation (1). The rationale for selecting $[\sin (2 \pi k t / T), \cos (2 \pi k t / T)]$ is based on the fact that a Fourier expression is capable of approximating absolutely integrable functions to any desired degree of accuracy, where $k$ represents the frequency selected for the approximation, and $\left[a_{i}, b_{i}\right]^{\prime}$ measures the amplitude and displacement of the frequency component. It also follows that if there is a structural break, at least one frequency component must be present. ${ }^{2}$ Gallant (1981), Becker et al. (2004), Enders and Lee (2012) and Pascalau (2010) demonstrate that a Fourier approximation can often capture the behavior of an unknown function even if this function itself is not periodic. As there is no a priori

\footnotetext{
${ }^{2}$ Enders and Lee (2012) suggest that the frequencies in (2) should be obtained via the minimization of the sum of squared residuals. However, their Monte Carlo experiments suggest that no more than one or two frequencies should be used, due to the loss of power associated with a larger number of frequencies.
} 
knowledge concerning the shape of the breaks in the data, a grid-search is first performed to find the best frequency. Next, we turn to the SPSM process which is based on the following steps:

(1) The IPS test with a Fourier function is first conducted on $H E_{i, t}$. If we fail to reject the null hypothesis of a unit root (i.e., $\delta_{i}=0$ ), then the procedure stops and we conclude that all series in the panel are non-stationary. If the null is rejected (i.e., $\left.\delta_{i}<0\right)$, then we can continue to Step 2;

(2) The series with the minimum IPS statistic is removed since it is identified as being stationary;

(3) We return to Step 1 for the remaining series, or stop the procedure if all the series are removed from the panel.

The final step is the separation of the whole panel into a set of mean-reverting series and a set of non-stationary series, if any.

\section{DATA AND EMPIRICAL RESULTS}

We make use of annual data on Healthcare Expenditure (HCE) from 1966 to 2009 for 50 US states. Data were obtained from the Center for Medicare and Medicaid Services Health Expenditures by State of Residence. This database reports total personal health care spending by state and by service. Data are expressed in per capita terms, by dividing with population figures, obtained from the regional database of the 
Bureau of Economic Analysis (BEA). Given that state-level CPI is not available for the entire period under study, the nominal per capita health care expenditures are converted to their real values by deflating with the aggregate US CPI. ${ }^{1}$ Note, we transform the data into their natural logarithmic values before building the ratios, as discussed in Section 2. Figure A1 in the Appendix plots the $H E_{i, t}$ for each of the 50 states, with the states being divided into the nine census divisions for the sake of clearly observing the trend in our variable of interest, which is even more pronounced if all states are plotted independently.

We start out the analysis with the standard IPS test with a trend in the specification. However, the null hypothesis of unit root cannot be rejected even at the 10 percent level of significance, with the test statistic generating a value of -1.7998 . This result is in line with the general lack of convergence into a single club, as reported in Wang (2009) and based on time series based tests. As discussed earlier, given the evidence of structural breaks in the health care expenditures, we next carry out the analysis with the modified IPS test which now includes the Fourier function. The new test statistic turns to be -2.9617 , implying that the null of a unit root is rejected at the 1 percent level of significance. ${ }^{3}$ However, since the overall statistic

\footnotetext{
${ }^{1}$ We would like to thank Donald G. Freeman, Sam Houston State University, for providing the dataset.

${ }^{3}$ For the sake of completeness, we also implemented the IPS test with only a constant, and with and without the Fourier function. In the former case, the null hypothesis of unit root could not be rejected even at the 10 percent level of significance, with the test statistic generating a value of -1.4031 . In the
} 
does not provide any information as to which of the states are driving this result of stationarity for the entire panel, we turn to the SPSM process. The results are reported in Table I. At the 5 percent level of significance, convergence is observed across all states, barring New Jersey and Arkansas. However, if we allow our inferences to be based at the 10 percent level of significance, we find overwhelming evidence of convergence in the health care expenditures across all 50 states. $^{4}$

An important related question is what causes this convergence? As indicated by Freeman (2012), real per capita personal disposable income is considered to be one of the main drivers of health care expenditures. Therefore, we explore whether real per capita personal disposable income also converges, using the same specification as in equation 1. As with the health care expenditures, our metric is the ratio of real per capita personal disposable income for a specific state at a specific point in time, case we included the Fourier function, the null of a unit root was rejected at the 1 percent level of significance, with the value of the IPS test statistic being -2.1655 . However, when we implemented the SPSM methodology, we found that only 11 out of the 50 states were showing evidence of convergence in health care expenditures. However, given the data plots which clearly showed a trend in the data, the more accurate specification of the IPS test should include a trend and a stronger rejection of the null in the case where the IPS test equation specification includes a trend vindicates our point.

${ }^{4}$ As a robustness check, using the club clustering methodology of Phillips and Sul (2007), we also obtained strong evidence of convergence in the real per capita health care expenditures, as suggested by the presence of only one convergence club across all 50 states. The time-varying convergence paths also indicated that convergence across the states started to take place quite early in the sample period, with complete convergence taking place towards the end of the same period. Complete details of these results are available upon request from the authors. Note that in the Phillips and Sul (2007) approach, the metric of interest is the natural logarithmic values of real per capita health care expenditures. 
Table I. IPS unit root tests (constant and trend) with Fourier function and SPSM for $H E_{i, t}$

\begin{tabular}{|c|c|c|c|c|c|}
\hline Sequence & IPS & $p$-value & Minimum IPS & $I(0)$ series & $k$ \\
\hline 1.0000 & -2.9617 & 0.0000 & -3.2435 & Kansas & 5.0000 \\
\hline 2.0000 & -2.9386 & 0.0000 & -3.1506 & Michigan & 5.0000 \\
\hline 3.0000 & -2.9042 & 0.0000 & -3.1171 & Illinois & 5.0000 \\
\hline 4.0000 & -2.8796 & 0.0000 & -3.0904 & Maryland & 5.0000 \\
\hline 5.0000 & -2.8728 & 0.0000 & -2.6693 & Delaware & 5.0000 \\
\hline 6.0000 & -2.8646 & 0.0000 & -2.6359 & Hawaii & 5.0000 \\
\hline 7.0000 & -2.8594 & 0.0000 & -2.6322 & South Dakota & 5.0000 \\
\hline 8.0000 & -2.8548 & 0.0000 & -2.6059 & Nevada & 5.0000 \\
\hline 9.0000 & -2.827 & 0.0000 & -2.5562 & Rhode Island & 5.0000 \\
\hline 10.0000 & -2.8332 & 0.0000 & -2.5088 & Utah & 5.0000 \\
\hline 11.0000 & -2.8038 & 0.0000 & -2.3314 & Montana & 5.0000 \\
\hline 12.0000 & -2.7719 & 0.0000 & -2.2877 & Massachusetts & 5.0000 \\
\hline 13.0000 & -2.7953 & 0.0000 & -2.2854 & Texas & 5.0000 \\
\hline 14.0000 & -2.7921 & 0.0000 & -2.1638 & New Mexico & 5.0000 \\
\hline 15.0000 & -2.7781 & 0.0000 & -2.1580 & Minnesota & 5.0000 \\
\hline 16.0000 & -2.7652 & 0.0000 & -2.1157 & Colorado & 5.0000 \\
\hline 17.0000 & -2.7591 & 0.0000 & -2.1018 & Iowa & 5.0000 \\
\hline 18.0000 & -2.7511 & 0.0000 & -2.0992 & Indiana & 5.0000 \\
\hline 19.0000 & -2.7502 & 0.0000 & -2.0952 & North Dakota & 5.0000 \\
\hline 20.0000 & -2.7513 & 0.0000 & -2.0821 & Arizona & 5.0000 \\
\hline 21.0000 & -2.6344 & 0.0000 & -2.0709 & Alaska & 5.0000 \\
\hline 22.0000 & -2.6415 & 0.0000 & -2.0706 & New Hampshire & 5.0000 \\
\hline 23.0000 & -2.6573 & 0.0000 & -2.0611 & Wyoming & 5.0000 \\
\hline 24.0000 & -2.6427 & 0.0000 & -1.9958 & Virginia & 5.0000 \\
\hline 25.0000 & -2.5215 & 0.0000 & -1.9381 & Missouri & 5.0000 \\
\hline 26.0000 & -2.5008 & 0.0000 & -1.9218 & West Virginia & 5.0000 \\
\hline 27.0000 & -2.4727 & 0.0001 & -1.8599 & Kentucky & 5.0000 \\
\hline 28.0000 & -2.4134 & 0.0003 & -1.8432 & Ohio & 5.0000 \\
\hline 29.0000 & -2.359 & 0.0009 & -1.8064 & Oklahoma & 5.0000 \\
\hline 30.0000 & -2.3183 & 0.0012 & -1.7686 & California & 5.0000 \\
\hline 31.0000 & -2.2748 & 0.0015 & -1.7558 & Idaho & 5.0000 \\
\hline 32.0000 & -2.2449 & 0.0012 & -1.6722 & Vermont & 5.0000 \\
\hline 33.0000 & -2.2203 & 0.0021 & -1.6580 & Mississippi & 5.0000 \\
\hline 34.0000 & -2.1847 & 0.0023 & -1.6031 & Wisconsin & 5.0000 \\
\hline 35.0000 & -2.2226 & 0.0013 & -1.5466 & New York & 5.0000 \\
\hline
\end{tabular}




\begin{tabular}{|cccccc|}
\hline 36.0000 & -2.2326 & 0.0008 & -1.5332 & Pennsylvania & 5.0000 \\
37.0000 & -2.5055 & 0.0002 & -1.4117 & Florida & 5.0000 \\
38.0000 & -2.3805 & 0.0006 & -1.3985 & Connecticut & 5.0000 \\
39.0000 & -2.3698 & 0.0007 & -1.3646 & Louisiana & 5.0000 \\
40.0000 & -2.1371 & 0.0054 & -1.0259 & Nebraska & 5.0000 \\
41.0000 & -2.2831 & 0.0009 & -0.9806 & Maine & 5.0000 \\
42.0000 & -2.3042 & 0.0027 & -0.9545 & North Carolina & 5.0000 \\
43.0000 & -2.2931 & 0.0023 & -0.7777 & Washington & 5.0000 \\
44.0000 & -2.4304 & 0.0019 & -0.6773 & Oregon & 5.0000 \\
45.0000 & -2.2464 & 0.0047 & -0.5956 & Georgia & 5.0000 \\
46.0000 & -1.7887 & 0.0964 & -0.5892 & New Jersey & 5.0000 \\
47.0000 & -1.7196 & 0.0553 & -0.5043 & Arkansas & 5.0000 \\
48.0000 & -2.5968 & 0.0091 & 0.0160 & South Carolina & 5.0000 \\
49.0000 & -2.7915 & 0.0013 & 0.3255 & Alabama & 5.0000 \\
50.0000 & -3.6753 & 0.0030 & 0.4887 & Tennessee & 5.0000 \\
\hline
\end{tabular}

Notes:

$\mathrm{HE}_{\mathrm{i}, \mathrm{t}}$ is the ratio of real per capita health care expenditures for a specific state at a specific point in time, divided by the cross-sectional average of real per capita health care expenditures across all 50 US states at that same point in time. The significance level is set at $10 \%$ for inferences. The maximum lag is set to at 4 , chosen by the Schwarz Information Criterion (SIC). The $p$-values are computed by means of 10,000 bootstrap replications. Fourier $(k)$ is chosen by minimizing the sum square of residuals of the Fourier function. 
divided by the cross-sectional average of real per capita personal disposable income across the 50 US states at that same point in time. If this ratio $\left(P D I_{i, t}\right)$ is stationary for a specific state $i$, then this state has convergent dynamics in terms of real per capita personal disposable income. Data on nominal personal disposable income are obtained from the regional database of the BEA, and then is converted to their per capita and real values by dividing with the population and CPI, respectively.

Figure A2 in the Appendix plots the $P D I_{i, t}$ for the 50 US states, again clubbed together based on the census divisions. The trend in the data is clearly visible. The IPS test with a trend and Fourier function generates a test statistic of -3.485 , implying the rejection of the null of a unit root at the 1 percent level of significance. Next, we now implement the SPSM and the results are reported in Table II. There is strong evidence in favor of convergence of the real per capita personal disposable income across all states at the 1 percent level of significance for 49 states (except Tennessee), and across all states at the 5 per cent level of significance. ${ }^{5}$

Overall, the empirical analysis provides overwhelming evidence in favor of convergence (broken trend-stationary) in real per capita health care expenditures across the 50 US states, which is shown to be the result of convergence in real per

\footnotetext{
5 Interestingly however, the methodology of Phillips and Sul (2007) indicates that the null hypothesis of a single convergent club for real per capita personal disposable income is rejected, suggesting the presence of three clubs. Complete details of these results are available upon request.
} 
Table II. IPS unit root tests (constant and trend) with Fourier function and SPSM for

\begin{tabular}{|c|c|c|c|c|c|}
\hline \multicolumn{6}{|c|}{$P D I_{i, t}$} \\
\hline Sequence & IPS & $p$-value & Minimum IPS & $I(0)$ series & $k$ \\
\hline 1.0000 & -3.485 & 0.0000 & -5.1917 & Nebraska & 5.0000 \\
\hline 2.0000 & -3.4254 & 0.0000 & -4.5126 & Washington & 5.0000 \\
\hline 3.0000 & -3.3878 & 0.0000 & -4.3301 & Arizona & 5.0000 \\
\hline 4.0000 & -3.3328 & 0.0000 & -4.3264 & Iowa & 5.0000 \\
\hline 5.0000 & -3.269 & 0.0000 & -3.3530 & Illinois & 5.0000 \\
\hline 6.0000 & -3.2389 & 0.0000 & -3.0983 & South Dakota & 5.0000 \\
\hline 7.0000 & -3.2082 & 0.0000 & -3.0380 & Rhode Island & 5.0000 \\
\hline 8.0000 & -3.2043 & 0.0000 & -2.9878 & Mississippi & 5.0000 \\
\hline 9.0000 & -3.1893 & 0.0000 & -2.9840 & Kentucky & 5.0000 \\
\hline 10.0000 & -3.1739 & 0.0000 & -2.9530 & North Dakota & 5.0000 \\
\hline 11.0000 & -3.1536 & 0.0000 & -2.9191 & Hawaii & 5.0000 \\
\hline 12.0000 & -3.1354 & 0.0000 & -2.8306 & Minnesota & 5.0000 \\
\hline 13.0000 & -3.1002 & 0.0000 & -2.7347 & New York & 5.0000 \\
\hline 14.0000 & -3.0691 & 0.0000 & -2.6636 & Pennsylvania & 5.0000 \\
\hline 15.0000 & -3.0899 & 0.0000 & -2.6410 & Maryland & 5.0000 \\
\hline 16.0000 & -3.0496 & 0.0000 & -2.6356 & Maine & 5.0000 \\
\hline 17.0000 & -3.0425 & 0.0000 & -2.6333 & Massachusetts & 5.0000 \\
\hline 18.0000 & -3.0424 & 0.0000 & -2.6190 & Arkansas & 5.0000 \\
\hline 19.0000 & -3.0384 & 0.0000 & -2.6135 & Louisiana & 5.0000 \\
\hline 20.0000 & -3.0571 & 0.0000 & -2.6071 & New Hampshire & 5.0000 \\
\hline 21.0000 & -3.0988 & 0.0000 & -2.6013 & Delaware & 5.0000 \\
\hline 22.0000 & -3.1233 & 0.0000 & -2.5916 & Alaska & 5.0000 \\
\hline 23.0000 & -3.0743 & 0.0000 & -2.5495 & Florida & 5.0000 \\
\hline 24.0000 & -3.0419 & 0.0000 & -2.4450 & Missouri & 5.0000 \\
\hline 25.0000 & -3.0483 & 0.0000 & -2.4343 & Kansas & 5.0000 \\
\hline 26.0000 & -3.0587 & 0.0000 & -2.3773 & Colorado & 5.0000 \\
\hline 27.0000 & -3.0458 & 0.0000 & -2.3047 & Indiana & 5.0000 \\
\hline 28.0000 & -3.0099 & 0.0000 & -2.2983 & Ohio & 5.0000 \\
\hline 29.0000 & -2.9689 & 0.0000 & -2.2318 & Connecticut & 5.0000 \\
\hline 30.0000 & -2.9956 & 0.0000 & -2.1565 & Idaho & 5.0000 \\
\hline 31.0000 & -3.0164 & 0.0000 & -2.1434 & New Mexico & 5.0000 \\
\hline 32.0000 & -2.9671 & 0.0000 & -2.1422 & West Virginia & 5.0000 \\
\hline 33.0000 & -2.9721 & 0.0000 & -2.1108 & Texas & 5.0000 \\
\hline 34.0000 & -2.9687 & 0.0000 & -2.1010 & Vermont & 5.0000 \\
\hline 35.0000 & -3.0073 & 0.0000 & -2.0823 & Wisconsin & 5.0000 \\
\hline
\end{tabular}




\begin{tabular}{|cccccc|}
\hline 36.0000 & -2.9943 & 0.0000 & -1.9471 & Nevada & 5.0000 \\
37.0000 & -2.9437 & 0.0000 & -1.9066 & Oregon & 5.0000 \\
38.0000 & -2.8881 & 0.0000 & -1.8820 & Utah & 5.0000 \\
39.0000 & -2.9436 & 0.0000 & -1.8569 & Oklahoma & 5.0000 \\
40.0000 & -2.9149 & 0.0001 & -1.8287 & California & 5.0000 \\
41.0000 & -2.7382 & 0.0014 & -1.6538 & Montana & 5.0000 \\
42.0000 & -2.6044 & 0.0039 & -1.5519 & New Jersey & 5.0000 \\
43.0000 & -2.726 & 0.0020 & -1.4411 & Alabama & 5.0000 \\
44.0000 & -2.891 & 0.0022 & -1.4137 & Virginia & 5.0000 \\
45.0000 & -3.4711 & 0.0006 & -1.1134 & Michigan & 5.0000 \\
46.0000 & -3.5784 & 0.0004 & -1.0947 & Wyoming & 5.0000 \\
47.0000 & -3.8866 & 0.0000 & -0.6598 & South Carolina & 5.0000 \\
48.0000 & -3.7262 & 0.0008 & -0.6543 & Georgia & 5.0000 \\
49.0000 & -3.4948 & 0.0052 & -0.4680 & North Carolina & 5.0000 \\
50.0000 & -3.5424 & 0.0184 & 0.0067 & Tennessee & 5.0000 \\
\hline
\end{tabular}

Notes:

$\mathrm{PDI}_{\mathrm{i}, \mathrm{t}}$ is the ratio of real per capita personal disposable income for a specific state at a specific point in time, divided by the cross-sectional average of real per capita personal disposable income across all 50 US states at that same point in time. The remaining notes are similar to those in Table I. 
capita personal disposable income, which is believed to be the main driver of health care expenditures.

At this stage it is important to specify that given the evidence of cross-sectional dependence, as indicated by Pesaran's (2004) test for both our metrics on health care expenditures and personal disposable income, ${ }^{6}$ the critical values for the modified IPS test are obtained using 10,000 bootstrap replications.

\section{CONCLUSIONS}

Current time-series evidence on convergence of real per capita health care expenditures across the 50 US states into a single club is nil. Against this backdrop, using a modified version of the panel-based IPS unit root test that accommodates for smooth structural changes using a Fourier function, we provided strong evidence in favor of convergence. In addition, implementing the SPSM methodology, we observed that the evidence of convergence in the entire panel is in fact driven by convergence in each of the 50 US states and not just a few cross-sectional units. Using the same methodology, we also determined that this convergence was possibly due to the presence of convergence in real per capita personal disposable income, which in

\footnotetext{
${ }^{6}$ The test statistics obtained for the metric for the health care expenditure and personal disposable income equals $2.8036(p$-value $=0.0051)$, and $-3.3282(p$-value $=0.0009)$, respectively, implying the rejection of the null of cross-sectional independence in both cases.
} 
the health literature, has been indicated to be the main driver of health care expenditures.

The results highlight the importance of modeling for structural breaks in the unit root tests, since if structural breaks are not accounted for, the study reverts back to earlier results in the literature showing no evidence of convergence. From a policy perspective, these results imply that common policies relating to the health care system can be pursued across all US states, since the health market is not disaggregated once we allow for smooth structural changes in the data generating process.

\section{REFERENCES}

Aslan A. 2008. Convergence of per capita health care expenditures in OECD Countries. MPRA Paper, No. 10592.

Becker R, Enders W, Lee, J. 2004. A general test for time dependence in parameters. Journal of Applied Econometrics 19: 899-906.

Canarella G, Miller SM, Pollard SK. 2012. Unit roots and structural change: An application to US house-price indices. Urban Studies 49: 757-776.

Carrion-i-Silvestre JL. 2005. Health care expenditure and GDP: Are they broken stationary? Journal of Health Economics 24: 839-854.

Chang T, Wu TP, Gupta R. 2015. Are house prices in South Africa really nonstationary? Evidence from SPSM-based panel KSS test with a Fourier function. Applied Economics 47: 32-53.

Chortareas G, Kapetanios G. 2009. Getting PPP right: identifying mean-reverting real exchange rates in panels. Journal of Banking and Finance 33: 390-404.

Enders W, Lee J. 2012. A unit root test using a Fourier series to approximate smooth breaks. Oxford Bulletin of Economics and Statistics 74: 574-599.

Fallahi F. 2011. Convergence of total health expenditure as a share of GDP: Evidence 
from selected OECD countries. MPRA Paper, No. 51324.

Freeman DG. 2012. Is health care a necessity or a luxury? New evidence from a panel of US state-level data. Sam Houston State University Economics and International Business Working Paper, No. 12-03.

Gallant AR. 1981. On the bias in flexible functional forms and an essentially unbiased form: The Fourier flexible form. Journal of Econometrics 15: 211-245.

Hitiris T. 1997. Health care expenditure and integration in the countries of the European Union. Applied Economics 29: 1-6.

Hitiris T, Nixon J. 2001. Convergence of health care expenditure in the EU countries. Applied Economics Letters 8: 223-228.

Hofmarcher MM, Riedel M, Röhrling G. 2004. Health expenditure in the EU: Convergence by enlargement?. IHS Health System Watch.

Im KS, Pesaran MH, Shin Y. 2003. Testing for unit roots in heterogeneous panels. Journal of Econometrics 115: 53-74.

Maddala GS, Kim IM. 1998. Unit Roots, Cointegration, and Structural Change. Cambridge University Press.

Narayan PK. 2006. Examining structural breaks and growth rates in international health expenditures. Journal of Health Economics 25: 877-890.

Narayan PK. 2007. Do health expenditures 'catch-up'? Evidence from OECD countries. Health Economics 16: 993-1008.

Narayan PK, Narayan S. 2008. Does environmental quality influence health expenditures? Empirical evidence from a panel of selected OECD countries. Ecological Economics 65, 367-374.

Narayan PK, Narayan S. 2008. The role of permanent and transitory shocks in explaining international health expenditures. Health Economics 17: 1171-1186.

Narayan PK. 2009. Are health expenditures and GDP characterized by asymmetric behaviour? Evidence from 11 OECD countries. Applied Economics 41: 531-536.

Narayan PK. 2010. Modelling health and output at business cycle horizons for the USA. Health Economics 19: 872-880.

Narayan PK, Popp S. 2012. A nonlinear approach to testing the unit root null hypothesis: an application to international health expenditures. Applied Economics 44: 163-175.

Narayan PK, Narayan S, Smyth R. 2011. Is health care really a luxury in OECD countries? Evidence from alternative price deflators. Applied Economics 43: 3631-3643.

Nixon J. 1999. Convergence analysis of health care expenditure in the EU countries using two approaches. The University of York Discussion Papers in Economics, No. 1999/03. 
Okunade AA, Karakus MC, Okeke C. 2004. Determinants of health expenditure growth of the OECD countries: Jackknife resampling plan estimates. Health Care Management Science 7: 173-183.

Pekkurnaz D. 2015. Convergence of health expenditure in OECD countries: Evidence from a non-linear asymmetric heterogeneous panel unit root test. Journal of Reviews on Global Economics 4: 76-86.

Pascalau R. 2010. Unit root tests with smooth breaks: An application to the NelsonPlosser data set. Applied Economics Letters 17: 565-570.

Pesaran HM. 2004. General diagnostic tests for cross section dependence in panels. Cambridge Working Papers in Economics, No. 0435.

Phillips PC. Sul, D., 2007. Transition modeling and econometric convergence tests. Econometrica 75: 1771-1855.

Rettenmaier AJ, Wang Z. 2006. Persistence in Medicare reimbursements and personal medical accounts. Journal of Health Economics 25: 39-57.

Wang Z. 2009. The convergence of health care expenditure in the US states. Health Economics 18: 55-70. 


\section{APPENDIX}
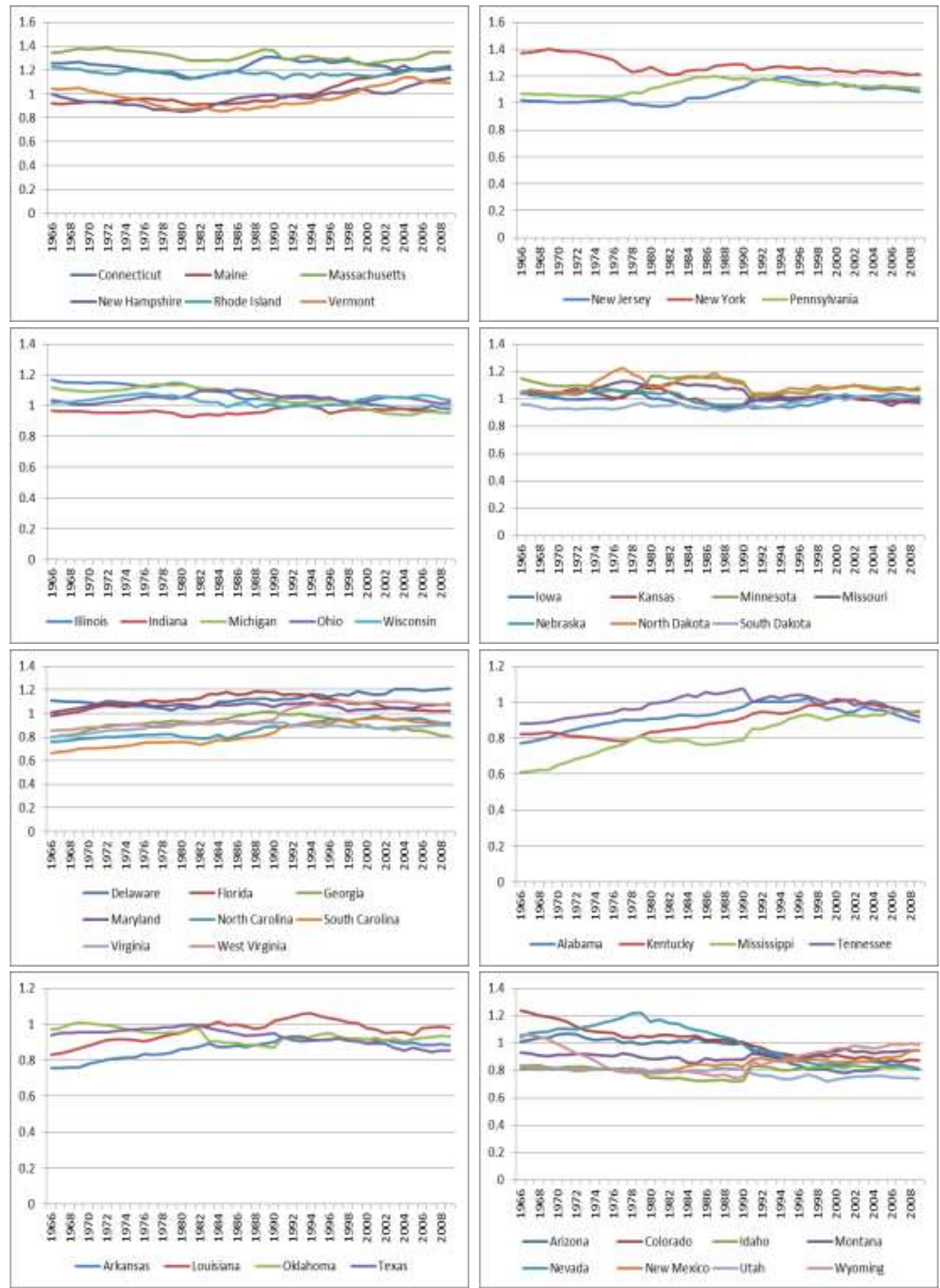


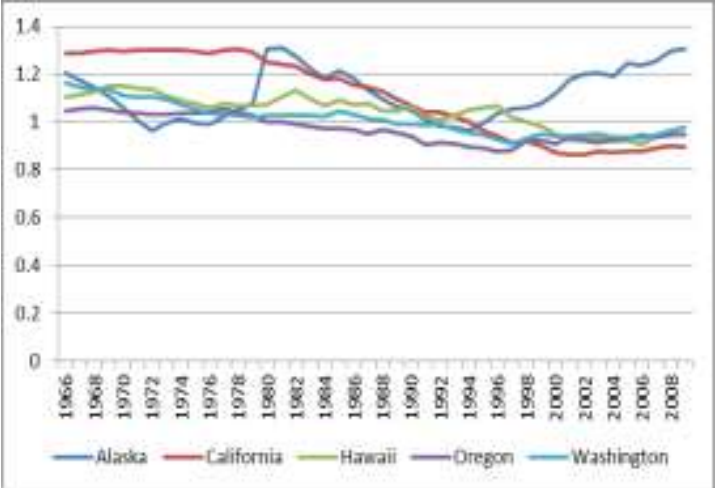

Figure A1. Convergence metric of real per health care expenditures 

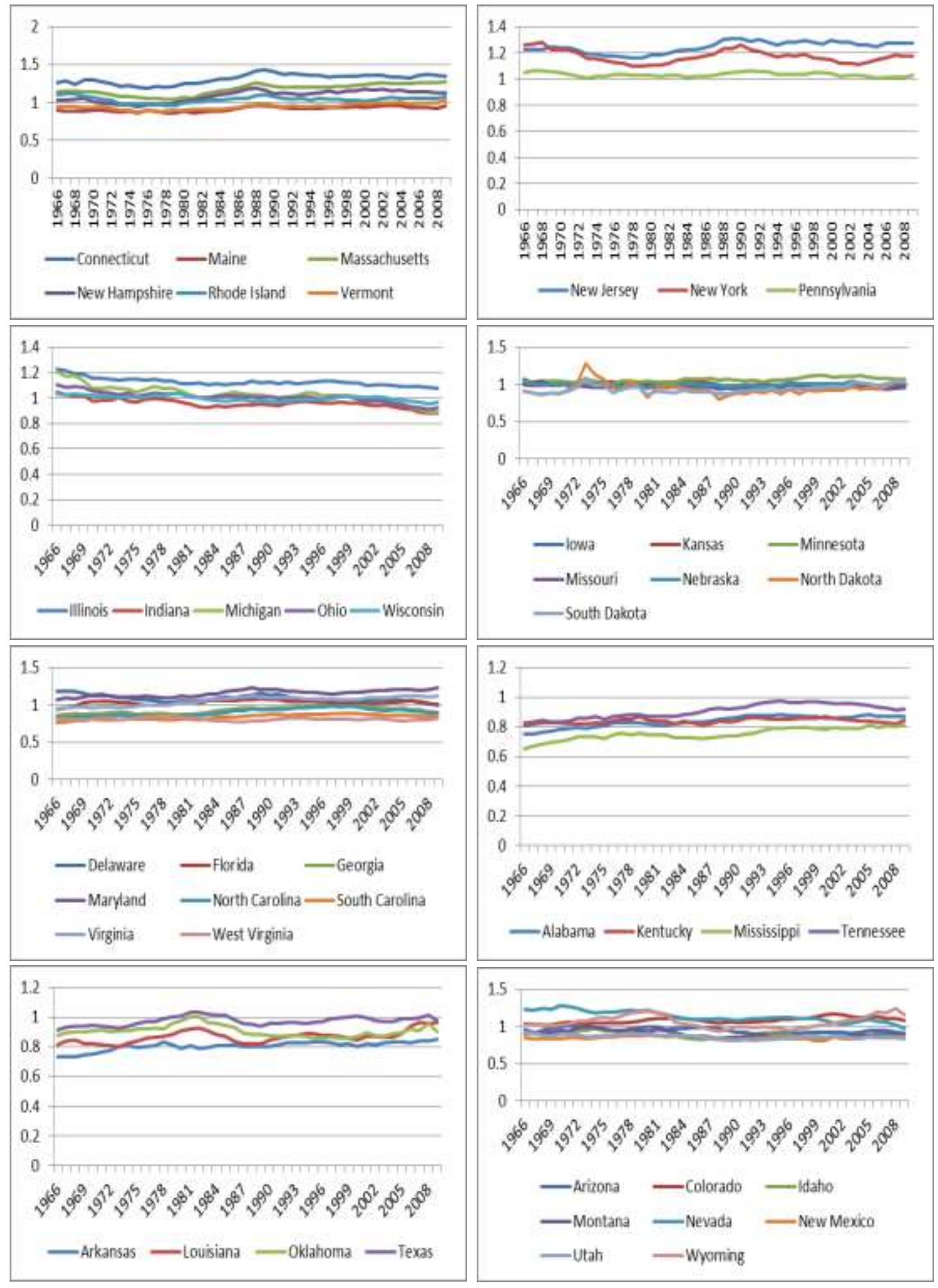


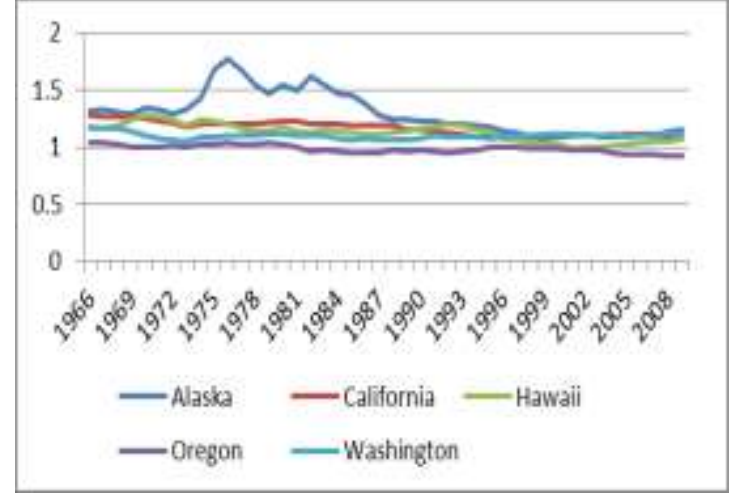

Figure A2. Convergence metric of real per capita personal disposable income 